\title{
Evaluation of Bone Marrow Derived Mesenchymal Stem Cell Potency on Wound Healing
}

\section{Somia $\mathrm{HA}^{1}$, Faten $\mathrm{ZM}^{2 *}$ and Shimaa $\mathrm{HA}^{2}$}

${ }^{1}$ Department of Biochemistry, Faculty of Medicine, Zagazig University, Egypt

${ }^{2}$ Department of Biochemistry, Faculty of Science, Zagazig University, Egypt

\begin{abstract}
Background: Wound healing is a complicated process of skin repair after injury. This process requires a coordinated interplay among cells, growth factors, and extracellular matrix proteins. Mesenchymal stem cell coordinates the repair response by recruiting other host cells and secreting growth factors and matrix proteins also they are self-renewing multipotent stem cells that can differentiate into various lineages of mesenchymal origin such as bone, cartilage, tendon, and fat. In addition to multilineage differentiation capacity, MSCs regulate immune response and inflammation and possess powerful tissue protective and reparative mechanisms, making these cells attractive for treatment of different diseases.
\end{abstract}

Aim: The beneficial effect of exogenous bone marrow-derived mesenchymal stem cell on wound healing was observed but the mechanisms involved are barely understood. In this study, we examined signaling factors released by stem cells and their effects on the cells participating in wound healing .

Materials and Methods: Thirty female mice were randomly divided into three groups and were anesthetized and full thickness, wide deep wounds were made , then the $2^{\text {nd }}$ generation of stem cells were injected intraperitoneally and intraregionally. These mice observed till complete healing then reverse transcription polymerase chain reaction was done for genes.

Results: This study found that bone marrow-derived mesenchymal stem cell promote the wound healing process.

Keywords: SRY; Collagen; Fibroblasts; IMDM; ICAM-1; Integrins

\section{Introduction}

Wound healing is a highly regulated process that is thought to be mediated in part by stem cells. They may also play a role in the reduction of scar formation and increased the tensile strength of healed incisional wounds. Many parts of the human body can heal after being wounded, but few wounds heal seamlessly. The new seam, or patch, is called a scar. Scars are mainly connective tissue and cannot replicate the specialized functions of the original injured tissue. In the skin, scars are covered by a layer of epidermis. Scars are imperfect replacements for damaged tissue, but scars are a natural result of healthy healing. When the healing situation is not ideal, scars are more likely to become problems. After poor healing, some scars become unnecessarily large or unnecessarily weak. For example, infections, tissue necrosis, sebaceous skin, and wounds perpendicular to natural lines of minimal skin tension will all lead to scars that are larger than normal [1]. Cutaneous wound healing is accomplished through the coordinated activity and recruitment of several cell types including keratinocytes, inflammatory cells, endothelial cells (ECs), and fibroblasts [2] and [3]. It is characterized by a series of partially overlapping phases, such as coagulation, inflammation, reepithelialisation/granulation tissue generation, scar formation and remodelling [4]. Immediately after injury, the platelets form a fibrin clot and release growth factors and chemokines all of which contribute to inflammation and angiogenesis induction, and to activate keratinocyte and fibroblast functions. Leukocyte extravasation, which involves selectin- and integrin-dependent trans-endothelial migration, is driven by several chemoattractants which initially recruit poly morpho nuclear cells (PMNs) into the wound [5]. The PMNs remove cellular debris and bacteria and stimulate angiogenesis and re-epithelialisation. Recent studies have demonstrated that treatment of cutaneous wounds with bone marrow-derived mesenchymal stem cells accelerates wound healing kinetics, increases epithelializationand increases angiogenesis [6]. Mesenchymal stem cells, or MSCs, are multipotent stromal cells that can differentiate into a variety of cell types, including: osteoblasts, chondrocytes and adipocytes. This phenomenon has been documented in specific cells and tissues in living animals and their counterparts growing in tissue culture [7]. Accumulating evidence indicates that mesenchymal stem cells may also promote tissue repair by secreting paracrine signals that improve responses to injury by resident skin cells. Wounds treated with mesenchymal stem cell-conditioned medium had accelerated wound closure and increased recruitment of macrophages and endothelial progenitor cells into the wound [8]. In addition, bone marrow-derived mesenchymal stem cells secrete a soluble chemoattractant for macrophages, keratinocytes and cells. Minor skin wounds heal well without treatment;however, extensive full-thickness wounds such as those that result from poly trauma or burns require intervention to heal in a timely manner without excessive scarring. Clinical studies have suggested that topical delivery of MSCs may improve chronic wound healing [9].

\section{Material and Methods}

\section{Materials}

- IMDM (sigma Aldrich, USA)

*Corresponding author: Faten Zahran Mohammed, Department of Biochemistry, Faculty of Science, Zagazig University, Egypt, Tel: 01000710580 ; Email: dr_fzahran@yahoo.com

Received October 25, 2015; Accepted October 27, 2015; Published October 29 , 2015

Citation: Somia HA, Faten ZM, Shimaa HA (2015) Evaluation of Bone Marrow Derived Mesenchymal Stem Cell Potency on Wound Healing. J Stem Cell Res Ther 5: 312. doi:10.4172/2157-7633.1000312

Copyright: ( 2015 Somia HA, et al. This is an open-access article distributed under the terms of the Creative Commons Attribution License, which permits unrestricted use, distribution, and reproduction in any medium, provided the original author and source are credited. 
- Trypan blue/PBS (0.4\%)(sigma Aldrich, USA)

- $1 \%$ Pencillin Streptomycin-AmphoteracinB mixture (10IU/ 10IU/2.5ug,100ml) (LonzaBioproducts,Belgium)

- $\quad 0.25 \%$ trypsin/ethylene diamine tetra acetic acid (EDTA) (LonzaBioproducts,Belgium)

- $\quad$ VEGF ELISA kit (Wkea med supplies corp,USA)

- RNA Extraction Mini Kit(Sigma Aldrich,USA)

\section{Chemicals}

All chemicals used in these experiments were provided with high quality and purity.

\section{Animal model}

For this study ten male mice aging one month and weighed $20 \mathrm{~g}$ were used for extraction of mice bone marrow-derived mesenchymal stem cell (MSCs), and thirty healthy female mice aging 6 months and weighed between 40-50 g were used. The thirty female mice were fed and water under controlled temperature $\left(25^{\circ} \mathrm{C}-30^{\circ} \mathrm{C}\right)$. To ensure adequate adaptation, they were observed in this environment for 7 days prior to commencing treatment.

\section{Experimental design}

This study was done according to animal rights. All animal procedures were conducted according to guidelines provided by Zagazig University Institutional Animal Care and Use Committee under an approved protocol. The thirty female mice were randomly divided into three groups and these female mice were anesthetized and 6-mm full thickness, 4-cm wide deep wounds were made. Group1: Ten wounded mice without bone marrow derived mesenchymal stem cells (MSCs). Group2: Ten wounded mice were injected with mice bone marrow derived mesenchymal stem cells intraperitoneally. Group3: Ten wounded mice were injected with mice bone marrow derived mesenchymal stem cells intraregionally (Figure 1).
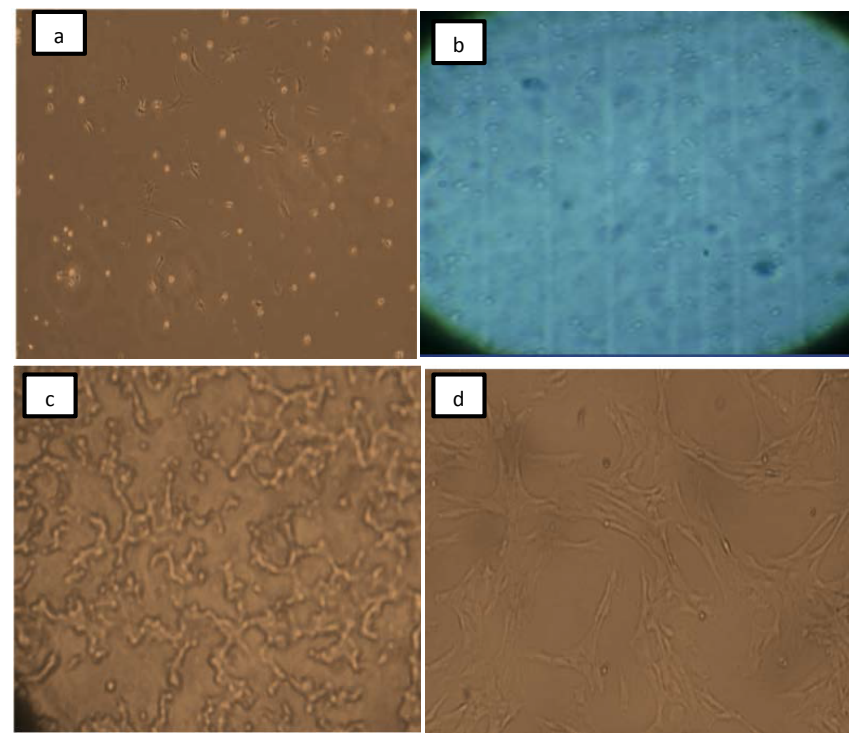

Figure 1: (a) Mesenchymal stem cells culture at day 1 which show the morphological spindle shape of the MSCs. (b) Mesenchymal stem cells viability as the viable cells are transparent while un viable cells are blue.(c) Mesenchymal stem cells culture after the first passage.(d) Mesenchymal stem cells culture after the second passage.
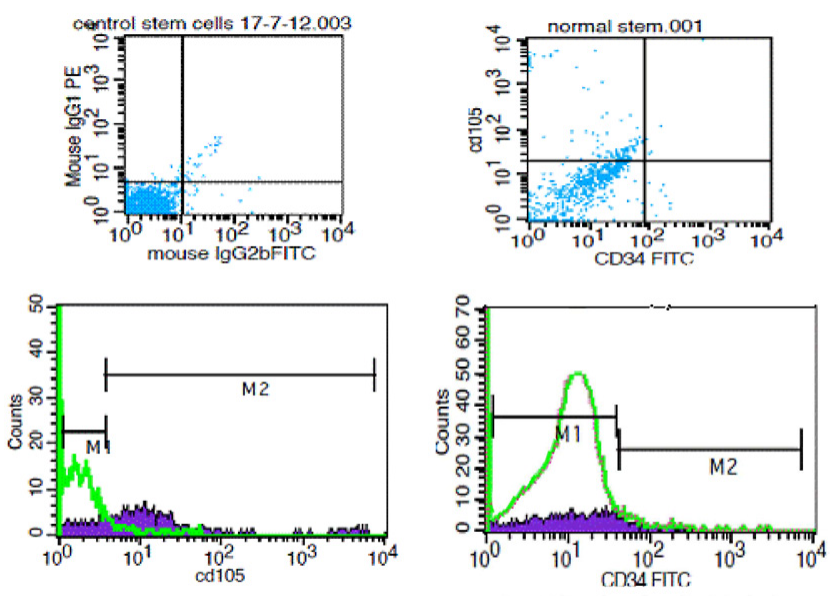

Figure 2: Flow cytometry analysis of cell surface markers in mesenchymal stem cells (MSCs).

\section{Isolation of mesenchymal stem cells from mice BM (Modified from Masoud Soleimani and Samad Nadri 2009)}

To isolate marrow, kill mice (4 weeks old) by cervical dislocation. Then, rinse the animal skeleton freely in $70 \%$ ethanol, make an incision around the perimeter of the hind limbs where they attach to the trunk and remove the skin. Then, dissect the hind limbs from the trunk of the body and the femur and tibiae were harvested by flushing IMDM. Store limbs on ice in IMDM (Sigma, Aldrich) supplemented with 1\% penicillin/streptomycin Amphoteracin (Lonza Bioproducts,Belgium) while awaiting further dissection.BM was harvested in a hood using proper sterile technique. A $10 \mathrm{ml}$ syringe inserted into the spongy bone exposed by removal of the growth plate. The marrow was flushed out of the cut end of the bone with $1 \mathrm{ml}$ of complete media. A dispersed bone marrow cell suspension as then prepared by repeated pipetting of the cell suspension with needles gauged 18 for proper mixing and the suspension mixed well with vortex, then centrifuged at 3000 RPM for $10 \mathrm{~min}$. To remove remaining particulates of fat or bone then the pellet washed and centrifuged two times with phosphate buffer saline (PBS) (Lonza Biobroducts, Belgium). The result pellet was diluted with PBS. Nucleated cells were isolated with adenisty gradient Ficoll/ Paque by taking $4 \mathrm{ml}$ of diluted bone marrow were slowly folded in the same amount of lymphocyte separation medium (Lonza Biobroducts, Belgium) then centrifuged on to $400 \mathrm{RPM}$ for $20 \mathrm{~min}$ in cooling centrifuge at $20^{\circ} \mathrm{C}$.

Bone marrow mononuclear cell were separated and then the collected interface cells moved into another centrifuge tube, then PBS wash with 2000RPM centrifugation for $5 \mathrm{~min}$ that repeated two times with discard the supernatant (Figure 2).

Test of cell viability: Before culture, cells were tested to detect their viability by trypan blue test , the dye was diluted with PBS ( 0.4 trypan blue /PBS) and then 100ul of the sample was added to equal volume of dye .Viable cell do not take blue Color (Figure 3).

Culture of separated mononunclear cells from mice: The mononuclear cell suspension obtained was [10] re suspended in complete culuture medium high glucose IMDM, $4.5 \mathrm{~g} / \mathrm{L}$ glucose with L-glutamine (Lonza Bioproducts, Belgium) containing 10\% FBS, 1\% Pencillin, streptomycin -Amphoteracin mixture (Lonza Bio products, Belgium).Cells were cultured at concentration of $5^{\star} 10^{6}$ per $25 \mathrm{~cm}^{2}$ 


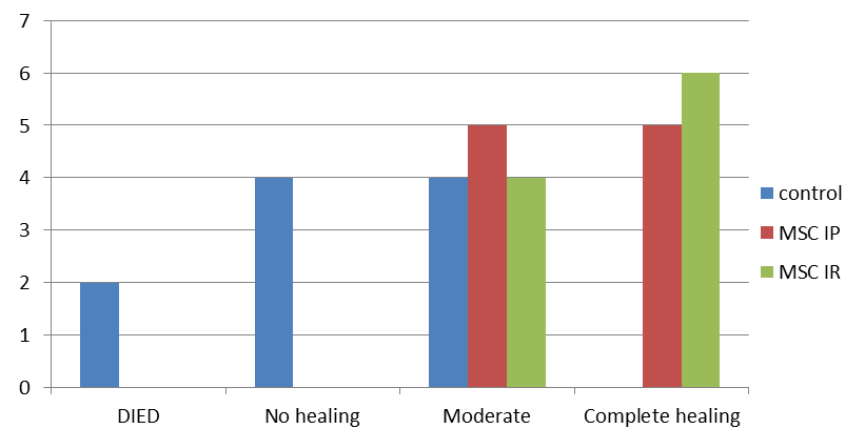

Figure 3: The relation between the three groups of female mice and the degree of healing after one week.

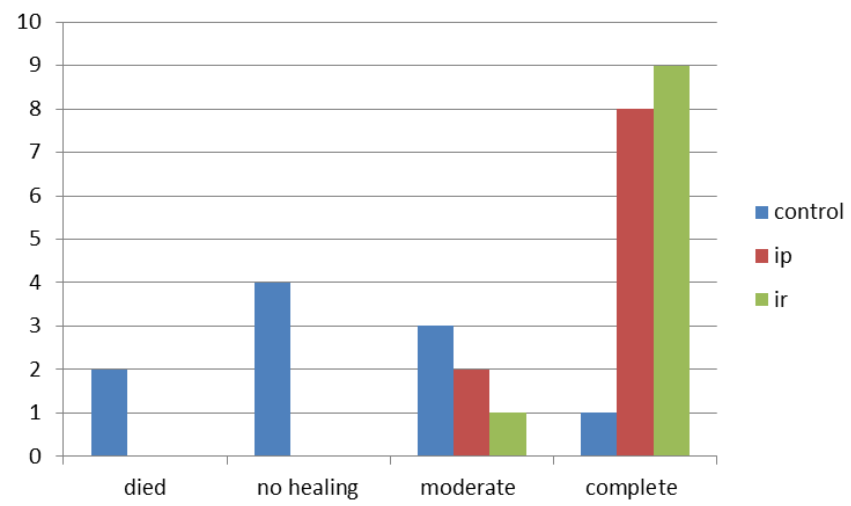

Figure 4 :The relation between the three groups of female mice and the degree of healing after twelve days.

culture flask then they were incubated at $37^{\circ} \mathrm{C}$ in $5 \%$ humidified $\mathrm{CO}_{2}$ incubator (Heraeus, Germany). The media were changed every 3-4 days (to remove non adherent cells). When large colonies developed (80-90\% confluence), culutures were washed twice with PBS and cells were trypsinized using $0.25 \%$ trypsin/ethylene diamine tetra acetic acid (EDTA) (Lonza Bio products, Belgium) for $5 \mathrm{~min}$ at $37^{\circ} \mathrm{C}$. After centrifugation (at $2400 \mathrm{RPM}$ for $20 \mathrm{~min}$ ), the resulting cultures were referred to as first passage culutures after 7 days.

Characterization of bone marrow derived mesenchymal stem cells: MSCs in culture $[11,12]$ were characterized by their adhesiveness and fusiform shape, by determination of surface markers of bone marrow derived mesenchymal stem cells that done by evaluation of the positive expression of $\mathrm{CD}_{105}$ surface marker and the negative expression of $\mathrm{CD}_{34}$ surface marker in MSCs that were analyzed by flow cytometer (Figures $4 \mathrm{a}$ and $4 \mathrm{~b}$ ).

Injection of bone marrow -derived mesenchymal stem cells into the mice: The formed colonies of the $2^{\text {nd }}$ generation were [13] injected intraperitoneally in each mice in the second group while intraregionally in the third group after the mice back skin were depilated.

Macroscopic wound analysis: Digital photographs of wounds were taken at day $0,3,5,8$ and 12 days. Time to wound closure was defined as the time at which the wound bed was completely re-epithelialized and filled with new tissue.

Estimation of serum VEGF level using VEGF ELISA kit (Wkea med supplies corp, USA): Samples were prepared [14] with serial dilution concentrations according to the manufacturing steps of the kit.

RNAextraction and reverse transcription polymerase chain reaction (RT-PCR): Skin specimen were homogenized until tissue clumps are no longer visible. Total RNA was isolated from skin tissue homogenate using IQeasy plus CTB RNA extraction kit (iNtRON Biotechnology, Korea). The extracted RNA was used for determination of ICAM-1, integrin beta 1and 2 , and Sry gene expression. The sequence of the primers used is listed as follow:

Sry gene : Forward 5-AGC GGC CAG GAA CGG GTC AAG3',Reverse 5`-CCT TCC GGC GAG GTC TGT ACT TG-3`

ICAM-1: Forward 5-AGG TGT GAT ATC CGG TAG A-3। ,Reverse 5`-CCT TCT AAG TGG TTG GAA CA-3

Integrin B1: Forward 5'- CTG ATT GGC TGG AGG AAT GT-3 ,Reverse 5'- TGA GCA ATT GAA GGA TAA TCA TAG-3'

Integrin B2: Forward 5'- AGT TCG ACT ACC CAT CCG TG-3 ,Reverse 5'- GTT GCT GGA GTC GTC AGA CA-3` (Sigma Aldrich, USA).RT-PCR reactions for the samples were performed .The target bands were visualized with an ultraviolet illuminator (Bio-Rad Laboratories Inc., Hercules, CA, USA).

Gel electrophoresis for separation of the genes: Loading of RNA sample then the device was turned on for a suitable time (20-25 min). The gel was then examined under the UV illuminator. The size of any resulting band was compared by 100bp M.W marker (Table 1).

Histological analysis of skin tissue: The sampled tissues were transferred to a cassette (a container designed to allow reagents to freely act on the tissue inside). The cassette is immersed in multiple baths of progressively more concentrated ethanol, to dehydrate the tissue, followed by xylene and finally hot liquid paraffin. Paraffin will replace the water in the tissue, turning soft, moist tissues into asample miscible with paraffin. The slides are then embedded in hematoxylin for $2 \mathrm{~min}$ (hematoxylin is used to stain the nuclei blue), then in eosin stain (eosin stains the cytoplasm and the extracellular connective tissue matrix pink).Then the slides examined to prove the good healing of the wounds or the infection [14].

\section{Statistical analysis}

Data were expressed as mean \pm standard error of the mean (SEM). Statistical analysis was performed by one-way ANOVA when more than two groups were present and .All statistical computations were performed using SPSS software (version 13.0) (Table 2).

\begin{tabular}{|l|c|c|c|}
\hline & Control group & MSC(IP) & MSC(IR) \\
\hline Died & $2 / 10$ & $0 / 10$ & $0 / 10$ \\
\hline No healing & $4 / 10$ & $0 / 10$ & $0 / 10$ \\
\hline Moderate healing & $4 / 10$ & $5 / 10$ & $4 / 10$ \\
\hline Complete healing & $0 / 10$ & $5 / 10$ & $6 / 10$ \\
\hline
\end{tabular}

Table 1: Results of clinical wound healing according to macroscopic signs after one week.

\begin{tabular}{|l|c|c|c|}
\hline Parameter & Control & MSC( IP) & MSC (IR) \\
\hline Integrin B1+B2 & $4 / 10$ & $8 / 10$ & $6 / 10$ \\
\hline B1integrin & $4 / 10$ & $3 / 10$ & $2 / 10$ \\
\hline B2integrin & $0 / 10$ & $5 / 10$ & $4 / 10$ \\
\hline ICAM-1 & $5 / 10$ & $5 / 10$ & $4 / 10$ \\
\hline
\end{tabular}

Table 2: The number of the female mice treated and not treated with stem cells that positively expressed the ICAM-1 gene, IntegrinB1 gene, and Integrin B2 gene. 


\section{Results}

Characterization of cultured mesenchymal stem cells (MSC) by flow-cytometry: Flow cytometric analysis of cell surface markers in mesenchymal stem cells (MSCs) expressed CD105, but did not express CD34. The surface markers expression pattern corresponds to bonemarrow derived mesenchymal stem cells (BM-MSCs).

Macroscopic wound analysis show that bone-marrow derived mesenchymal stem cells (BM-MSCs) enhance wound healing: To compare the wound healing signs among different groups macroscopic gross differences of the wound surface were observed (Figure 5). On day 2, all the wounds were covered with a little purulent fluid. Redness and swelling were detected. On day 5, size of wound was significantly reduced with formation of black scars and alleviation of the inflammatory responses in all groups. On day 8 some scars become deatached and part of new epidermis appeared in groups treated with mesenchymal stem cells.But little hair was found on the new epidermis. On day 12, complete healing occurred for most of the treated mice with stem cells and hair formed (Table 3 ).

Reverse transcription polymerase chain reaction (RT-PCR) results: RT-PCR examination of samples of skin tissues obtained from the three study groups had convincingly shown that the stem cells which was injected and separated from male mice had been incorporated into the structure of the skin of the female mice treated by stem cells. This was seen by finding that the groups that received stem cell injection

Day

0

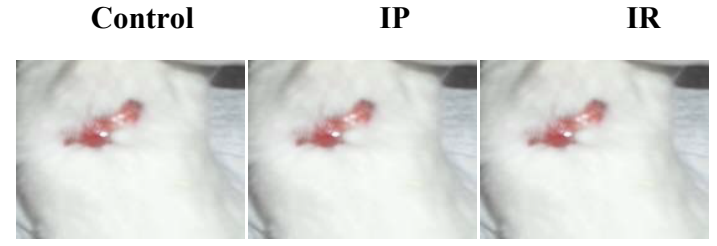

3

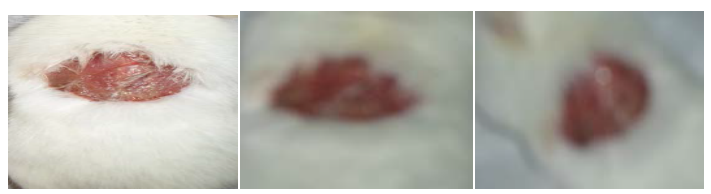

5
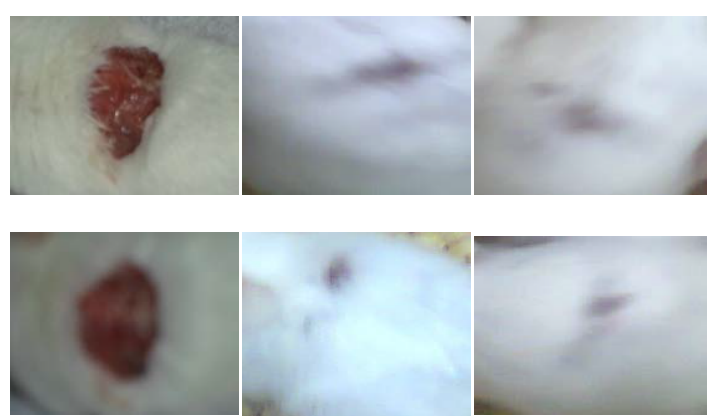

12
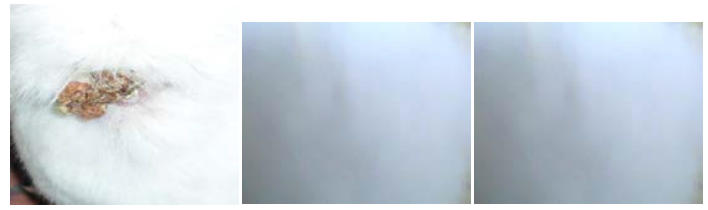

Figure 5: Representative images of wound healing at different time points .Apparently the wound size was significantly reduced in female mice treated with BM-MSCs compared to the female mice not treated with BM-MSCs.

\begin{tabular}{|c|c|c|}
\hline Control & MSC IR & MSC IP \\
\hline 78 & 100 & 215 \\
\hline 29 & 90 & 168 \\
\hline 63 & 76 & 301 \\
\hline 81 & 69 & 297 \\
\hline 62 & 120 & 98 \\
\hline 25 & 68 & 228 \\
\hline 70 & 130 & 300 \\
\hline 30 & 110 & 193 \\
\hline & 76 & 170 \\
\hline & 80 & 200 \\
\hline
\end{tabular}

Table 3: Serum vascular endothelial growth factor(VEGF) level in the three treated and non treated groups.

\begin{tabular}{|c|c|c|}
\hline parameter & $\mathrm{X}^{2}$ & P value \\
\hline Died & 4.29 & 0.11 \\
\hline No healing & 9.23 & 0.009 \\
\hline Moderate healing & 0.27 & 0.87 \\
\hline Complete healing & 8.9 & 0.011 \\
\hline
\end{tabular}

Table 4: Statistical analysis of clinical wound healing according to macroscopic signs after one week.

showed the sry gene while the control group lack of that gene (Table $4)$.

Histopathology results: Histological examination was done for the skin tissue of sacrificed female mice from the three groups after healing. As shown in Figure 6 after one week there is thicker granulation tissue in the group that treated with BM-MSCs than the group that not treated, also in day 12 reepithelialization and regeneration around the wound edge was the predominant process during the late stage of wound healing (Figure 7).

\section{Discussion}

Bone marrow has an extremely complex cellular arrangement of bone marrow stroma, to maintain the hemopoietic microenvironment. Other than hemopoietic stem cells and differentiated lineages, bone marrow contains a subset of nonhemopoietic cells, mesenchymal stem cells (MSCs) that account for roughly $0.01-0.001 \%$ of the bone marrow derived cell population [15]. Mesenchymal stem cells (MSCs) can differentiate not only into mesenchymal lineage cells but also into various other cell lineages. As MSCs can easily be isolated from bone marrow, they can be used in various tissue engineering strategies. In this study, we assessed whether MSCs can differentiate into multiple skin cell types including keratinocytes and contribute to wound repair. Recent reports show that MSCs may have the ability to differentiate into other lineage cells in vitro, such as endothelial cells, neural cells and hepatocytes. In vivo studies have also shown that MSCs can differentiate into tissue-specific cells in response to cues provided by different organs [15]. Normal wound healing is a dynamic and complex process involving a series of coordinated events, including bleeding and coagulation, acute inflammation, cell migration, proliferation, differentiation, angiogenesis, re-epithelialization, and synthesis and remodeling of the extracellular matrix [16,17]. Many factors can impair wound healing, including infection, tissue hypoxia, necrosis, exudates, and excess levels of inflammatory cytokines, which prolong one or more phases of inflammation, proliferation, or remodelling [18]. In this study, we cultured MSCs in culture medium, and have identified certain conditions under which MSCs efficiently differentiate into keratinocytes in vitro. Additionally, we have intraregionally and intraperitoneally injected MSCs into wounded mice, and have investigated whether 

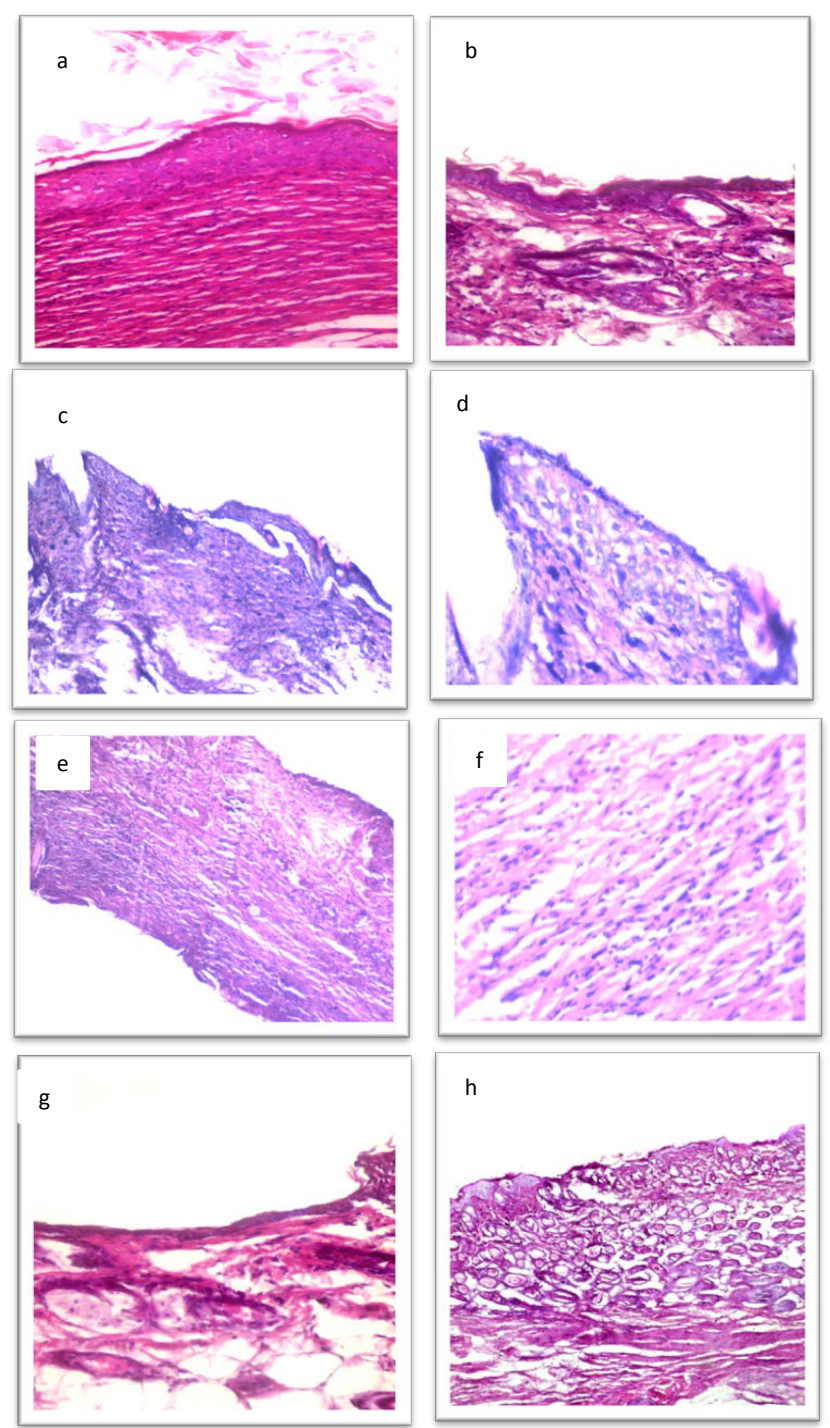

Figure 6: $H$ \&E staining of sections from skin of female mice (a),(b) treated with BM-MSCs intraperitoneally in group 2 ,that showing full thickness healed wound and keratinized stratified squamous epithelium overlaying collagen fibers and fibroblasts.(magnification $x$ 400).(c),(d) treated with BM-MSCs intraregionally, showing healed wound with full thickness proliferating epithelium with signs of regeneration.(e)(f) not treated with BM-MSCs showing infected granulation tissue formed of vascular spaces, fibroblasts and mononuclear inflammatory cells.(g) not treated with BM-MSCs after one week, showing no healed wound and ulcer in the skin.(h) treated with BMMSCs after one week, showing healing wound showing basal cell proliferation covering the raw area which is early signs of healing.

MSCs migrate and become engrafted into wounded skin to promote wound healing. This study aimed to clarify and evaluate the impact of BM-MSCs on the wound healing of skin tissue wounds in mice so this study was done on three groups: Group1: Ten wounded mice without bone marrow derived mesenchymal stem cells (MSCs). Group2: Ten wounded mice were injected with mice bone marrow derived mesenchymal stem cells intraperitoneally. Group3: Ten wounded mice were injected with mice bone marrow derived mesenchymal stem cells intraregionally. In this study we used the second generation of male mice prepared BM-MSCs to be injected. In the current study, the protocols published by [19] used for the isolation of mono nucleated

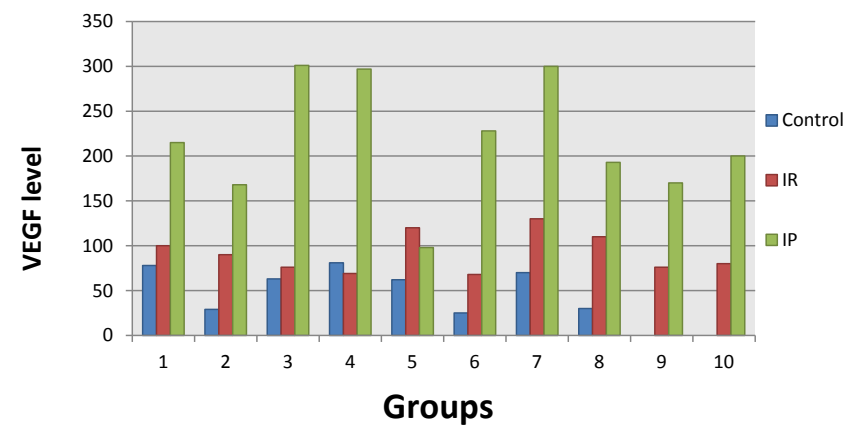

Figure 7:Diagram showing the relation between VEGF level(ng/l) in serum and the treated and non treated groups.

cells followed by the separation of MSCs by adherence to plastic, were modified to obtain good yield of cells. MSCs were evaluated by morphological parameters and its phenotype surface markers. We used the second generation of the growing MSCs to be injected into the female mice of the second and third group, as the most contaminating hematopoietic cells progressively lost after the second passage [20]. Freshly isolated MSCs have been shown to display enhanced homing ability compared to their culture expanded counterparts [21]. The prepared MSCs were extracted from male mice bone marrow then allogeneic transplantation was done to female mice to allow to detect the incorporation of MSCs into the recipient skin tissue by detecting the sry gene. The allogeneic transplantation was encouraged by the special property of MSCs as they are immunologically privileged, so allogeneic MSCs do not induce aproliferative T cell response [22]. The ways of injection used in this study is the intra peritoneal (IP) injection which is more common for small animals who cannot receive medications and fluids by other methods. With animals, an IP injection may be the only way to reliably deliver medication and reduce the accumulation of MSCs within filtering organs [21]. From molecular aspect the transmitted MSCs in the skin tissue of mice were detected by finding sry gene (derived from male mice bone marrow stem cells) within the skin tissue of the in female mice. The return of wounded skin tissue viability can be explained by the incorporation of the BM-MSCs within the skin tissue which in turn differentiated into different types of cells. In addition, the paracrine mediators represented in this study by VEGF that secreted by injected MSC might be involved in the repair as the VEGF prevent cell apoptosis, increase vascularity of tissues that help regeneration $[23,24]$. Also other genes were detected in the skin tissue samples of the three groups included firstly the ICAM-1 gene as ICAM-1 expression was assessed in the wounded skin in control group but In healed skins, ICAM-1 was detected exclusively on endothelial cells so wound healing, keratinocyte migration, and granulation tissue formation were significantly inhibited in the absence of ICAM-1 expression as it is important in stabilizing cell-cell interactions and facilitating leukocyte endothelial transmigration. Secondly, ITG- $\beta 1$ gene was expressed in the three groups as the integrin- $\beta 1$ plays a crucial role during skin development, postnatal physiology and wound healing. Betal integrin has been reported to be localised at the basolateral surface of basal keratinocytes of the epidermis. The loss of epithelial beta1 integrin causes extensive skin blistering, wound healing defects and a severely abnormal hair phenotype. Thirdly, ITG- $\beta 2$ was expressed in the three groups, as the migrating epidermal cells start dividing and proliferating in order to make epidermal cell sheets and cover the wound area. This process is called re-epithelialization. At the same time, the epidermal cells start producing some of the components of basement membrane in order to stabilize the structure of newly-formed 
epidermis. The fusion of moving epidermal sheets is associated with the production of a new integrins, called beta-2. From the results of our study the statistical analysis was done on groups $1,2,3$ considering the macroscopic wound healing at different times after one week through the study period. There was a higher significant difference $(p<0.009)$ for the non treated group than the other groups showed that the no healing signs in the non treated group is more than the other treated groups. Also the significant difference $(p<0.001)$ of the treated groups was higher than the non treated groups showed that the complete healing signs in the treated groups is more than the control group and in the same time these signs is higher in the intraregionally injected group when compared with the intraperitoneally injected group. While when the statistical analysis was done within groups 1,2,3 after twelve days there was a significant difference $(\mathrm{p}<0.009)$ of the non treated group higher than the other injected groups showed that the no healing signs in the control group is more than the treated group, on the second hand there was higher significant difference $(\mathrm{p}<0.0001)$ of the treated groups than the non treated groups which indicates more complete healing signs in the BM-MSCs treated groups than the control group. When the statistical analysis done on the treated and non treated groups considering the positive expression of ICAM- 1 , ITG- $\beta 1$, ITG- $\beta 2$ genes among groups found that the gene expression of integrin $\beta 2$ showed higher significant difference $(\mathrm{p}<0.035)$ in both the treated groups than the control group while the other genes of $\beta 1$ integrin and ICAM- 1 did not show significant difference as the $\beta 2$ integrin help in reepithelization of the new tissue so these results ensure that the BM-MSCs after introduction to the wounded skin region accelerate wound healing and wound closure. The concluded result was the persistence of wounds in group 1 while the recovery of the wounded mice in the other treated groups. This result was in agreement with [18]. These results agree with [25] who established a dermal fibrosis model induced by bleomycin and evaluated the benefit of bone marrow-derived mesenchymal stem cells (BM-MSCs) on skin fibrosis development. Tracing assay of green fluorescent protein $\left(\mathrm{GFP}^{+}\right) \mathrm{BM}$-MSCs showed that the cells disappeared gradually within 24 hours upon administration, which hinted the action of BM-MSCs in vivo was exerted in the initial phase of repair in this model. Therefore, we repeatedly transplanted syngeneic BM-MSCs in the process of skin fibrosis formation (Table 5). After 3 weeks, it was found that BM-MSC-treated lesional skin demonstrated a unanimous basket-weave organisation of collagen arrangement similar to normal skin, with few inflammatory cells. These findings suggested that BMMSCs can inhibit the formation process of bleomycin-induced skin fibrosis, alleviate inflammation and favour the remodelling of extracellular matrix [26] demonstrated the importance of bone marrow-derived mesenchymal stem cells (BM-MSCs) in the repair of damaged myocardium. Myocardial infarctions were created by permanent ligation of left anterior descending (LAD) coronary artery in $B A L B / c$ mice. In this study, reverse transcription-polymerase chain reaction was done for integrin $\beta 1$ and $\beta 2$ and ICAM-1which shown increased expression of these genes as they involved in cell-cell/cellmatrix interactions between ischemic myocardium and BM-MSCs so a significant reduction in the total number of BM-MSC in the infarcted myocardium was observed after integrin $\beta 1$ and $\beta 2$ blockade. From

\begin{tabular}{|c|c|c|}
\hline parameter & $\mathrm{X}^{2}$ & $\mathrm{P}$ value \\
\hline Died & 4.29 & 0.11 \\
\hline No healing & 9.23 & 0.009 \\
\hline Moderate healing & 1.25 & 0.33 \\
\hline Complete healing & 1.25 & 0.33 \\
\hline
\end{tabular}

Table 5: Statistical analysis of clinical wound healing according to macroscopic signs after twelve days.

\begin{tabular}{|c|c|}
\hline Groups & VEGF \&L SD Range \\
\hline Control & $54.5 \pm 23.4(25-81)$ \\
\hline Msc IR & $91.9 \pm 22.1(68-130)$ \\
\hline MSC IP & $217 \pm 66.7(98-301)$ \\
\hline
\end{tabular}

Table 7: Statistical analysis of vascular endothelial growth factor (VEGF) levels in serum of the studied groups $(F=39.55$; $P$ value $<0.001)$.

\begin{tabular}{|c|c|c|}
\hline parameter & $\mathrm{X}^{2}$ & $\mathrm{P}$ value \\
\hline Integrin $\beta 1+\beta 2$ & 3.33 & 0.18 \\
\hline B1integrin & 0.95 & 0.62 \\
\hline B2integrin & 6.67 & 0.035 \\
\hline ICAM-1 & 0.27 & 0.87 \\
\hline
\end{tabular}

Table 6: Statistical analysis for the treated and non treated mice that positively express the ICAM-1, ITG- $\beta 1$, ITG- $\beta 2$ genes.

biochemical aspect we analyzed VEGF serum levels after stem cell injection (Tables 6 and 7). The statistical analysis of the results showed higher significant difference $(\mathrm{p}<0.001)$ when compared the control group with the other treated groups. Also the serum levels showed a significant increase in the level of VEGF in the group that received MSC intraperitoneally than the group that received MSC intraregionally which ensured that the acceleration of wound healing in IP group more than IR group may be due to enhancement of VEGF secretion systematically and locally when MSC homed to wound. It is considered as an important mediator that mediates MSC mechanism of action [27] disagree with our result that showed that ICAM-1gene expressed more in the control group than the other treated groups after healing of the treated groups as their results ensured that there were no clear differences in the expression of ICAM-1 or VCAM-1 among groups. Our results confirms that IR injection of BM-MSCs into the wounded skin in mice accelerates wound healing, also it confirms that VEGF can be used as a measure of healing in MSC tissue regeneration.

\section{References}

1. Ito M, Liu Y, Yang Z, Nguyen J, Liang F, et al. (2005) Stem cells in the hair follicle bulge contribute to wound repair but not to homeostasis of the epidermis. Nat Med 11: 1351-1354. [PubMed]

2. Shaw TJ, Martin P (2009) Wound repair at a glance. J Cell Sci 122: 3209-3213. [PubMed]

3. Kondo T, Ishida Y (2010) Molecular pathology of wound healing. Forensic Sci Int 203: 93-98. [PubMed]

4. Baum CL, Arpey CJ (2005) Normal cutaneous wound healing: clinical correlation with cellular and molecular events. Dermatol Surg 31: 674-686. [PubMed]

5. Bellavia G, Pasquale F, Roberta M, Maurizio CC (2013) Transcriptional control of skin reepithelialisation. Journal of Dermatological Science.56-45.

6. Lin CD, Allori AC, Macklin JE, Sailon AM, Tanaka R, et al. (2008) Topica lineage-negative progenitor-cell therapy for diabetic wounds. Plast Reconstr Surg 122: 1341-1351. [PubMed]

7. Nardi N, Beyer d.a, Silva Meirelles L (2006) Mesenchymal Stem Cells: Isolation, In Vitro Expansion and Characterization. Handbook of experimental pharmacology 174: 24982.

8. Wu Y, Chen L, Scott PG, Tredget EE (2007) Mesenchymal stem cells enhance wound healing through differentiation and angiogenesis. Stem Cells 25: 26482659. [PubMed]

9. Wong VW, Levi B, Rajadas J, Longaker MT, Gurtner GC (2012) Stem cell niches for skin regeneration. Int J Biomater 2012: 926059. [PubMed]

10. Polisetti N, Chaitanya VG, Babu PP, Vemuganti GK (2010) Isolation, characterization and differentiation potential of rat bone marrow stromal cells. Neurol India 58: 201-208. [PubMed]

11. Alge DL, Zhou D, Adams LL, Wyss BK, Shadday MD, et al. (2010) Donor-matched comparison of dental pulp stem cells and bone marrow-derived mesenchymal stem cells in a rat model. J Tissue Eng Regen Med 4: 73-81. [PubMed] 
Citation: Somia HA, Faten ZM, Shimaa HA (2015) Evaluation of Bone Marrow Derived Mesenchymal Stem Cell Potency on Wound Healing. J Stem Cell Res Ther 5: 312. doi:10.4172/2157-7633.1000312

12. Leiker M, Suzuki G, lyer VS, Canty JM Jr, Lee T (2008) Assessment of a nuclear affinity labeling method for tracking implanted mesenchymal stem cells. Cell Transplant 17: 911-922. [PubMed]

13. Galeano M, Deodato B, Altavilla D, (2003) Adeno-associated viral vectormediated human vascular endothelial growth factor gene transfer stimulates angiogenesis and wound healing in the genetically diabetic mouse. Diabetologia, 46: 546-555.

14. Hirshfield AN, Midgley AR Jr (1978) Morphometric analysis of follicular development in the rat. Biol Reprod 19: 597-605. [PubMed]

15. Sasaki M, Abe R, Fujita Y, Ando S, Inokuma D, et al. (2008) Mesenchymal stem cells are recruited into wounded skin and contribute to wound repair by transdifferentiation into multiple skin cell type. J Immunol 180: 2581-2587. [PubMed]

16. Maxson S, Lopez EA, Yoo D, Danilkovitch-Miagkova A, Leroux MA (2012) Concise review: role of mesenchymal stem cells in wound repair. Stem Cells Transl Med 1: 142-149. [PubMed]

17. Eun Kyoung Jun, Qiankun Zhang , Byung Sun Yoon, Jai-Hee Moon, Gilju Lee, et al. (2014) Hypoxic Conditioned Medium from Human Amniotic Fluid-Derived Mesenchymal Stem Cells Accelerates Skin Wound Healing through TGF-ß/ SMAD2 and PI3K/Akt Pathways . Int J Mol Sci 15: 605-628

18. Wan J, Xia L, Liang W, Liu Y, Cai Q (2013) Transplantation of bone marrowderived mesenchymal stem cells promotes delayed wound healing in diabetic rats. J Diabetes Res 2013: 647107. [PubMed]

19. Soleimani M, Nadri S (2009) A protocol for isolation and culture of mesenchymal stem cells from mouse bone marrow. Nat Protoc 4: 102-106. [PubMed]
20. Lodie TA, Blickarz CE, Devarakonda TJ, He C, Dash AB, et al. (2002) Systematic analysis of reportedly distinct populations of multipotent bone marrow-derived stem cells reveals a lack of distinction. Tissue Eng 8: 739-751. [PubMed]

21. Karp JM, Leng Teo GS (2009) Mesenchymal stem cell homing: the devil is in the details. Cell Stem Cell 4: 206-216. [PubMed]

22. Humphreys BD, Bonventre JV (2008) Mesenchymal stem cells in acute kidney injury. Annu Rev Med 59: 311-325. [PubMed]

23. Shin SY, Lee JY, Lee E, Choi J, Yoon BK, et al. (2006) Protective effect of vascular endothelial growth factor (VEGF) in frozen-thawed granulosa cells is mediated by inhibition of apoptosis. Eur J Obstet Gynecol Reprod Biol 125: 233-238. [PubMed]

24. Fu X, He Y, Xie C, Liu W (2008) Bone marrow mesenchymal stem cell transplantation improves ovarian function and structure in rats with chemotherapy-induced ovarian damage. Cytotherapy 10: 353-363. [PubMed]

25. Wu Y, Huang S, Enhe J, Ma K, Yang S, et al. (2014) Bone marrow-derived mesenchymal stem cell attenuates skin fibrosis development in mice. Int Wound J 11: 701-710. [PubMed]

26. Ip JE, Wu Y, Huang J, Zhang L, Pratt RE, et al. (2007) Mesenchymal stem cells use integrin beta1 not CXC chemokine receptor 4 for myocardial migration and engraftment. Mol Biol Cell 18: 2873-2882. [PubMed]

27. Chang P, Qu Y, Liu Y, Cui S, Zhu D, et al. (2013) Multi-therapeutic effects of human adipose-derived mesenchymal stem cells on radiation-induced intestinal injury. Cell Death Dis 4: e685. [PubMed] 